\title{
A Comparison of High Speed Internet Service in Ghana: An Analytical Hierarchy Approach
}

\author{
Michael F. Frimpon \\ Graduate School of Business \\ Ghana Institute of Management and Public Administration \\ Accra, Ghana \\ Ebenezer Adaku ${ }^{1}$ \\ Graduate School of Business \\ Ghana Institute of Management and Public Administration \\ Accra, Ghana
}

Please cite this article as: Frimpon, M.F. and Adaku, E. (2018), "A comparison of high-speed internet service in Ghana: an analytical hierarchy approach", Information Technology \& People, Vol. 31 No. 1, pp. 181-198.

${ }^{1}$ Corresponding author: E. Adaku

E-mail: eadaku@gimpa.edu.gh 


\title{
A Comparison of High Speed Internet Service in Ghana: An Analytical Hierarchy Approach
}

\begin{abstract}
Purpose - The rising proportion of internet users in Sub-Sahara Africa (SSA) and the lack of analytical techniques, as decision support systems, in choosing among alternative Internet Service Providers (ISPs) by consumers underpin this study. The study proposes an approach for evaluating high speed internet service offered by ISPs in a sub-Saharan African country

Design/methodology/approach - Using a sample size of 150, pairwise comparisons of two ISPs along five criteria of cost, usability, support, reliability and speed were performed by 10-person groups of university students working in various organizations in Ghana and undertaking an online six sigma course. Geometric means were employed to aggregate the scores in 15 groups, and these scores were then normalized and used as input into an Analytical Hierarchy Process (AHP) grid.

Findings - The results show that consumers of internet services highly emphasize the cost attribute of internet provision in their decision making. On the other hand, it was realized that consumers least emphasize the support provided by ISPs in their decision making among alternative ISPs.

Originality/value - This study has sought to provide an analytical framework for assessing the quality of service provided by alternative ISPs in a developing economy's context. The evaluating criteria in this framework also reveal the key consumer requirements in internet service provision in a developing economy's environment. This, to a large extent, will inform the marketing strategies of existing ISPs in Ghana as well as prospective ones intending to enter the Ghanaian market. Besides, the National Communication Authority (NCA), a regulator of communication services provision in Ghana, will be informed about the performances of the ISPs along five performance criteria. This is expected to aid in their regulatory functions.
\end{abstract}


Keywords - Decision support systems, Developing countries, End user, IT Services, User Satisfaction, AHP.

Article type - Research paper

\section{Introduction}

Though the internet is useful, its penetration and usage in Sub Sahara Africa (SSA) is still low relative to other developing worlds. Generally in the developing world, $31 \%$ of the population has access to the internet, compared with $77 \%$ in the developed world. In Africa, $16 \%$ of people have access to the Internet even though penetration is projected to hit the 50\% mark by 2019 (Sanou, 2013). The achievement of such a goal requires some pragmatic strategies, given the fiscal challenges of most countries in SSA. Fortunately, the emergence of the Wireless Internet Technology (WIT) offers a good pathway due to its lower cost relative to the Fixed Line Technology (FLT). There have been significant investments in internet infrastructure in developed countries (Shin, 2009). These investments are largely in FLT, however attention now, in those countries, is being given to investments in the WIT due to its relatively cheaper cost (Schumann and Kende, 2013). Incidentally, in recent times, there has been a massive growth in WIT in SSA due to its relatively lower cost. Currently the ratio of WIT to FLT in respect of internet access is 9:1 in SSA (Minges et. al, 2009).

The main source of internet service in Sub-Saharan Africa (SSA) comes from the mobile phone cellular towers scattered across the region owned and operated by the telecommunication companies (Telecoms). Generally, two devices [smartphones and Universal Serial Bus (USB) modems] are the main means of receiving internet from the cellular towers. An actual modem device is approximately the same size and shape of a typical USB flash pen drive. A small subscriber identification module (SIM) card - exactly the same type used in mobile phones - is inserted into a USB modem to give the modem its unique identification - similar to how a SIM card gives a unique identification to a mobile phone. The USB modem comes with a software 
that allows a network connection to a nearby cellular tower so the computer can be connected to the internet (Singhal and Shukla, 2012; Reiffel, 2011).

There are six companies in Ghana which deal in telecommunication services in addition to offering internet data and accessibility. These six telecommunication companies (with their respective market shares on internet data in parentheses) are MTN (50.5\%), Vodafone (18.2\%), Airtel (14.4\%), Tigo (13.8\%), GLO (2.7\%) and Espresso (0.3\%) (NCA, 2014). Except for Espresso, the rest are multinationals. Besides, Vodafone is the only company that offers fixed line access to the web. Considerable resources are expended by the telecoms in marketing their internet products. However, it is not clear what informs the marketing strategy adopted by the management of these telecoms. Erevelles et al. (2003) indicate that there are relatively little studies on consumer satisfaction in Internet Service Provider (ISP) markets. Erevelles et al. (2003)'s assertion is with respect to developed countries and economies. Their view in the context of developing countries and economies is relatively worse. Incidentally, a recent study by Thaichon et al. (2014) further indicates that there is limited research in evaluating customers' purchase behaviour or satisfaction of internet services in Thailand (a developing economy) and advocates for more investigation in this important and highly under researched service sector. It is, therefore, therefore, to necessary to increase research on consumer satisfaction in ISP markets, especially in developing countries or economies. A study in this direction could potentially inform the marketing strategies and service deliveries of the ISPs in these economies. The focused marketing strategies and tailored service deliveries could boost the patronage of internet services and grow the ISP market. Growth in the ISP market will support the agenda to increase internet penetration and access in SSA.

Studies on consumer satisfaction and internet service provision (Adomi, 2005; Hussain et al. 2012; Guerrero, 2015, Frimpon 2016) are emerging in SSA. However, most of these studies are qualitatively approached in understanding the attributes of internet service and how these attributes rank in importance to consumers. This study attempts to take the research on consumer satisfaction in the ISP market, in SSA, a step further by employing a more rigorous or quantitative approach in understanding the underlying satisfaction processes of internet service consumers by using the Analytical Hierarchy Process (AHP). Some researchers (e.g. Geneletti, 2010, Ferretti, 2011 among others) have indicated the appropriateness of using multi-criteria 
decision approaches to making landfill sites decisions. The selection of an Internet Service Provider (ISP) (and for that matter internet service) can be viewed as a multi-criteria decision problem that requires an evaluation process of the criteria and how well the alternatives measure up on these identified criteria. Hence, this study, also, seeks to employ Analytical Hierarchy Process (AHP) (as a decision support system for consumers) to evaluate ISPs via their modems in how well they meet the needs of consumers with respect to internet provision. In addition, this study would aid the National Communication Authority (NCA), a regulator of communication services provision in Ghana, in their understanding of the performances of the ISPs. Such understanding would inform regulatory policies at NCA's end to ensure better internet services to consumers.

The rest of the study is structured into five sections. The first and second sections deal with introduction and application of the AHP model in decision making frameworks, respectively. The third section considers the AHP methodology and model development. The fourth section presents the results and discussions of the study. Finally, the fifth section provides some conclusions on the study and points out some areas for further or future studies.

\section{The ISP environment}

In an ISP environment, decisions made by consumers are largely informed by some underlying satisfaction processes which are predicated on the consumers' criteria and the service attributes. Hence, in order to build a model (as decision support system) to aid consumers in understanding how well alternative ISPs meet their needs and also to inform the ISPs about the underlying satisfaction processes of the consumers, some satisfaction criteria need to be identified. In the literature, there appears to be a degree of agreement among authors on key criteria (see Table 1) that are used by consumers in selecting an ISP service. Internet cost is an important criterion for selecting an ISP (Goh 1996; Smith 1997; Zeng et al., 2003; Rehman et al., 2011). In a study done in Nigeria, $72 \%$ of the respondents in a survey indicated the high cost of internet as a challenge to the internet market (Adomi, 2005). Whereas consumers in the Nigerian environment express sensitivity to cost, in the U.S environment cost is considered a basic criterion for considering an ISP. Other dimensions such as customer service and ease of use are more critical 
for consumers in choosing an ISP and also for ISPs to win new customers and to retain existing ones (Erevelles et al., 2003). The assertion of Erevelles et al. (2003) confirmed a similar study (Tan and Teo, 1998) in Singapore and corroborated another study (Li et al., 2008) in Taiwan. In the UK, ISP satisfaction survey indicated that reliability of internet service is the most important criterion for $78 \%$ of consumers and more than half of the consumers indicated they would switch to another ISP to have better reliability (McCue, 2006). The customer service dimension, as indicated by Erevelles et al. (2003) consist of criteria such as technical support, reliability of internet service and internet access speed. Besides, the ease of use dimension comprise criteria such as ease of software installation and user friendliness of software. Again, Vlachos and Vrechopoulos (2008) argue that consumers of internet services are motivated by the overall service quality which emanates from a stable (reliable) and fast internet network, quick response and customer support team that is trusted by customers. Thaichon et al. (2014) attempted to develop a model for assessing the service quality of ISPs by focusing on some elements that are deemed to impact on the overall quality of internet service. The elements included network quality (reliability and speed), customer service and technical support and website information support.

In establishing the consumer satisfaction criteria as a basis for comparing alternative ISPs, a definition and description of the consumer satisfaction criteria, especially from the Ghanaian perspective, is done to provide a contextual background to the study.

[Table 1]

\section{Cost}

Cost is a significant factor in selecting an ISP. Cost here is considered under two major sub criteria - fixed and variable costs. The fixed cost consists of the purchase cost of the modem hardware. The determination of the fixed cost is not straight forward because the ISPs always bundle free data with the modem upon purchase. The free data is significant enough to offset a considerable portion of modem purchase cost. So for most of the ISPs, the cost of the modem is almost free, and will thus not feature in the determination of cost in this study. 
On the other hand, the variable cost is the cost of data replenishment. This is the cost of data purchased regularly and for the average user is by far the more significant of the two costs.

Speed

Speed refers to the rate of delivery of the dispensed service which in this case is the data. Speed, is an important metric for consumers evaluating their broadband options and considering how they plan to use the Internet. Technically speed is split into two streams, download speed and upload speed. Download speed comes into play when one has to obtain information from the internet. Activities such as reading a webpage or downloading a program involve download speed. Upload speeds involve sending data over the internet. Activities such as sending email and syncing through Google Drive, Yahoo Dropbox and Microsoft SkyDrive involve upload Speed. Upload speeds are increasing in importance as users create and share more content and data. More ISPs are offering symmetrical services, where the download and upload speeds are equal, but most providers continue the standard practice of engineering their networks to maximize download speeds. Activities such as chatting typified by Facebook, Tweeting and WhatsApp usually involve both speeds.

\section{Usability}

Also referred to as "User-Friendliness", this attribute is a combination of factors that affect the

user's experience with the product. Factors such as the ease of understanding or understandability, the ease of figuring out how to use the product (learnability) and the presence of diagnostics to enable one monitor data usage and operate it properly (operability) all fall under usability.

\section{Reliability}

Reliability has good influence on overall service quality. Precision, accuracy and minimization of data losses are all measures of reliability. Internet modems in Ghana have peculiar features like stability and non-stability. Non-stability occurs in situations when sometimes modems will not start or take interminably long before they start, or data cuts off in mid-stream. Another feature like spiking is when high volumes of data are dispensed in spurts causing early depletion of purchased data. Latency, a common feature with the Ghanaian internet streaming, is where so little data is dispensed as to make webpages almost impossible to load; as a result the so-called little data is wasted because the webpage takes unduly long time to load. Over longer periods this 
can result in considerable amount of wastage. Good reliability requires a minimization and possible elimination of these events.

\section{Support}

The quality of support and its characteristics are of importance in the choice of an ISP modem. Support is considered from two perspectives, customer support and vendor support. Customer support in the delivery of data through the modem by an ISP is very significant. In the peculiar situation of Ghana where one vendor is the supplier of modems to almost all the competing alternatives or ISPs, then the importance of support shifts to ISP customer support. Hot line service; quality training; qualification of staff; technical support; continuous improvement, user groups are all considered attributes of customer support.

Considering this number of selection criteria coupled with the six alternative ISPs (MTN, Vodafone, Airtel, Tigo, GLO and Expresso), a considerable degree of complexity is introduced in decision making, especially for consumers of internet services. However, Analytical Hierarchy Process (AHP) appears to appropriately handle this complexity and provides a decision support system for consumers of internet services. Figure 1 shows a graphical structuring of the many processes and attributes involved in the decision model. 


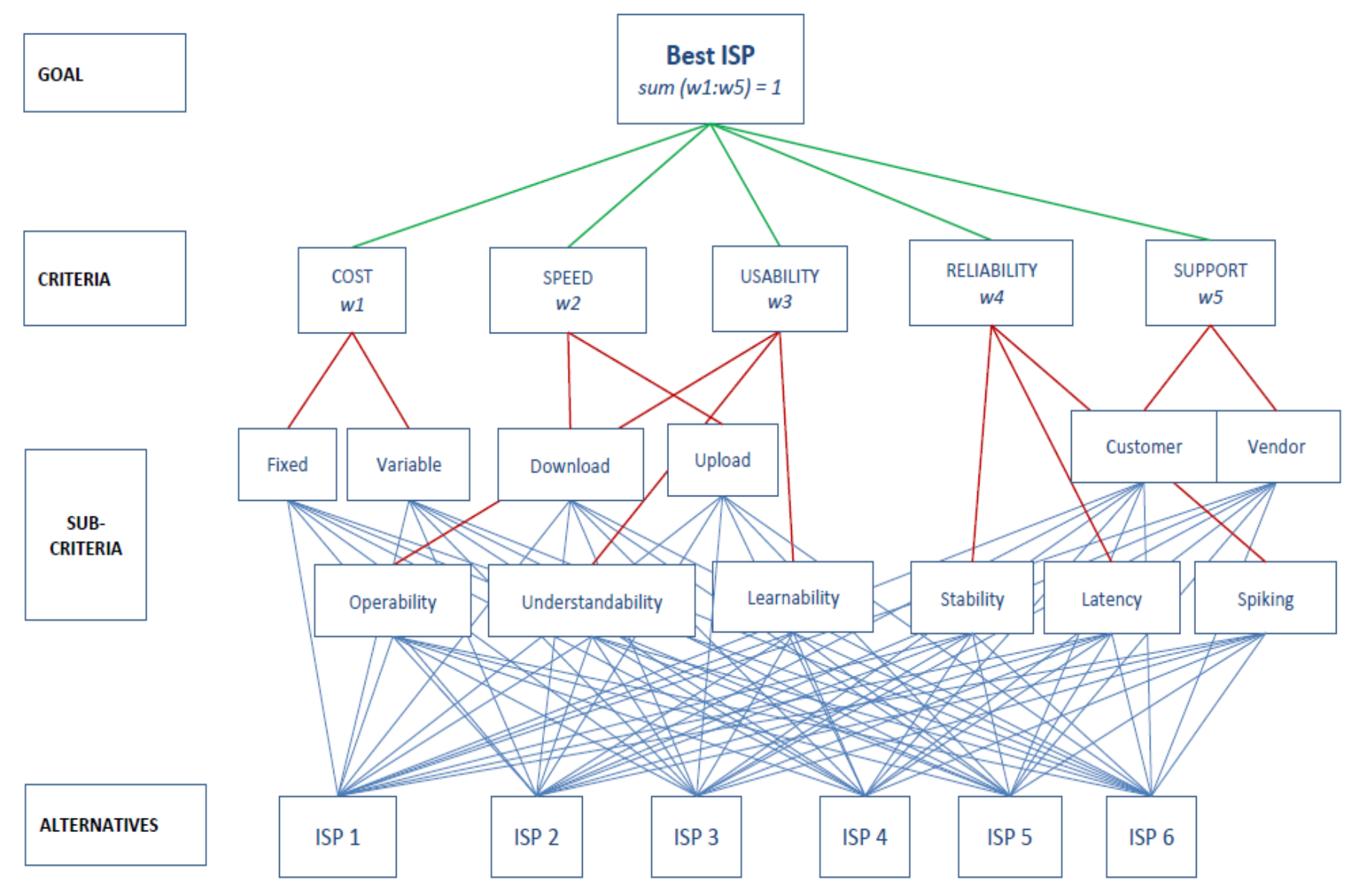

Figure 1: Decision Hierarchy of ISP Modem Selection 


\section{Analytical hierarchy process in research and practice}

The Analytical Hierarchy Process (AHP) is one of the most used multi-criteria decision-making approaches. The AHP is primarily used in the selection of an alternative among several alternatives in a multi-criteria environment. It is suitable for solving complex and challenging evaluation problems such as ERP selection, R\&D project selection, investment risk analysis, organizational planning, performance measurement, alternative selection, project evaluation and public policy analysis (Forgionne et al. 2002; Chow and Luk, 2005; Guh et. al, 2009).

The general validity of the AHP, and the confidence placed in its ability to resolve multiobjective decision situations, is based on the many and diverse applications in which the AHP results were accepted and used by decision makers (Saaty, 1994). Since its introduction in the mid-1970s by Saaty, AHP has been applied in a wide variety of practical applications in various fields including some areas such as car purchasing (Byun, 2001), vendor selection (Tam and Tummala, 2001), IS project selection (Muralidar and Santhanam, 1990; Schniedejans and Wilson, 1991), and software evaluation (Kim and Yoon, 1992; Ossadnik and Lange, 1999; Mamaghani, 2002; Ngai and Chan, 2005). It assists the decision making process by allowing decision-makers to organize the criteria and alternative solutions of a decision problem in a hierarchical decision model (Eldrandaly, 2007).

AHP combines tangible and intangible attributes to derive priorities associated with problem alternatives. AHP is a methodology for structuring, measurement and synthesis. Its principal mechanism of pair wise comparison of objectives and alternatives is intuitive and natural. The AHP's structured framework enables decision makers (DMs) to enhance their understanding of complex decisions by breaking the problem into smaller bits that fit in a hierarchical structure. Incorporating all relevant decision criteria and the pairwise comparisons permits DMs to trade-off among objectives (Mirkin, 1979; Guh, 2009).

AHP when used in a group setting, can:

- Accommodate both tangibles and intangibles, individual values and shared values in the group decision process,

- Help structure a group decision so that the discussion centers on objectives rather than on alternatives, 
- Allow discussion to continue until all available and pertinent information have been considered and a compromised choice of an alternative most likely to achieve the stated objectives is achieved (Dyer and Forman, 1992; Lai et al., 1999). In certain situations, focusing on alternatives instead of objectives is a recipe for bias and AHP helps to minimize that.

\section{Methodology}

Axioms of AHP

AHP is guided by the following set of axioms that give it its validity (Forman and Gass, 2001; Guh et. al, 2009):

1. Reciprocity: If criterion $\mathrm{ci}$ is $\mathrm{P}(\mathrm{ci}, \mathrm{cj})$ times more important than criterion $\mathrm{cj}$, then criterion $\mathrm{cj}$ is $1 / \mathrm{P}(\mathrm{ci}, \mathrm{cj})$ times as important as criterion ci. Reciprocity allows us to cut down on the number of comparisons.

2. Homogeneity: Only comparable elements are compared. It is essential for comparing similar things, as judgment errors become large when comparing very disparate elements.

3. Independence: The relative importance of elements at any level does not depend on what elements are included at a lower level.

4. Expectation: The hierarchy must include all the criteria and alternatives in the subject under study. No criteria and alternatives are left out and no excess criteria and alternatives are included.

\section{Pairwise Comparison Scale}

A predefined and agreed upon scale allows for a standardization of the comparisons. According to experts, an individual cannot compare more than nine things simultaneously without being confused, (Foster and Al-Dubaibi, 1995) so Saaty's $1-9$ scale is very relevant and is used more often as a scale of reference (Saaty, 2008)

There have been many descriptions, in literature; with regard to the intensity of comparison. Among them are "significance" and "importance". Table 4 (in Appendix) indicates a combination of multiple judgments as proposed by Saaty (2008). 


\section{AHP Problem Structure}

From the methodological point of view, the development of the AHP model applied in this study, involves the following steps after Ferretti (2011) and Coyle (2004):

1. Problem structuring and model development: This step consisted of developing the structure of the decision making process and involved defining the main objectives and identifying the criteria that influence the decision. This structure is indicated in Figure 1.

2. Raw data acquisition: Appropriately designed questionnaires were sent out to respondents for their perspectives on the service provisions of their ISPs compared with others.

3. Pair wise comparison and relative weight estimation: This step mainly was the identification of the relative importance of each element with respect to the others, in order to find the level of contribution of each element, be it a criterion or alternative to the achievement of its related objectives (weight assessment). In this pairing exercise, the smaller element was used as the unit and the larger element became an integer multiple of that unit with respect to the common property or criterion for which the comparisons were made. The main eigenvector of each pairwise comparison matrix represented the synthesis of the numerical judgments established at each level of the hierarchy.

4. Processing: At this stage, the aggregated scores of the respondents were input into a grid one at a time. The first cell is always a comparison of the first cell in the first column against the first cell in the topmost row. A comparison of any cell against itself is trivial and results in unity. Mathematically $\mathrm{P}(\mathrm{i}, \mathrm{i})=1$

\begin{tabular}{|l|c|c|c|c|c|}
\hline ELEMENT & Element1 & Element2 & Element3 & Element4 & Element5 \\
\hline Element1 & $\boldsymbol{a 1 1}$ & $a 12$ & $a 13$ & $a 14$ & $a 15$ \\
\hline Element2 & $\boldsymbol{a 2 1}$ & $\boldsymbol{a 2 2}$ & $a 23$ & $a 24$ & $a 25$ \\
\hline Element3 & $\boldsymbol{a 3 1}$ & $\boldsymbol{a 3 2}$ & $\boldsymbol{a 3 3}$ & $a 34$ & $a 35$ \\
\hline Element4 & $\boldsymbol{a 4 1}$ & $\boldsymbol{a 4 2}$ & $\boldsymbol{a 4 3}$ & $\boldsymbol{a 4 4}$ & $a 45$ \\
\hline Element5 & $\boldsymbol{a 5 1}$ & $\boldsymbol{a 5 2}$ & $\boldsymbol{a 5 3}$ & $\boldsymbol{a 5 4}$ & $\boldsymbol{a 5 5}$ \\
\hline
\end{tabular}

Figure 2: Population of AHP grid of dimension $n=5$

Beginning from the first cell $(\mathrm{a} 1,1)$ in Figure 2, the inputting was done by descending the black steps with each foot landing on the next diagonal element $[a(i, i)]$. If the pairwise comparisons to be effected are " $n$ ", then the sum (C) of the pairwise comparisons is as expressed in equation 1 : 


$$
C=\left[\frac{n(n-1)}{2}\right]
$$

when $\mathrm{n}=1$, there is no comparison since there is only one element and so $\mathrm{C}=0$.

6. Super matrices formation: This step consisted of the progressive formation of two super matrices - the unweighted and weighted ones. The unweighted super matrix contains all the eigenvectors that were derived from the pairwise comparison matrices of the model. The eigenvector obtained from the sub-objective level comparison, with respect to the general goal, was applied to the unweighted super matrix as a cluster weight to obtain the weighted super matrix.

7. Results aggregation: An overall index for each modem was calculated using an aggregation rule which is usually a composite of all the criteria appropriately weighted.

8. Sensitivity analyses: The aim of this step was to test the robustness of the results and the role played by uncertainty factors.

It is the essence of the AHP that human judgments, and not just the underlying information, is used in performing the evaluations (Saaty, 2008). At this pair wise comparison stage every cluster is compared against every other cluster. After that every element in a cluster is compared against other elements of the same cluster. This satisfies the principle of homogeneity. The pair wise comparisons' exercise is a systematic descending of the black staircase with each step landing on a diagonal element $\mathrm{P}(\mathrm{i}, \mathrm{i})=1$, where an element is compared against itself $[a(i, i)]$ as seen in Figure 2. Using the axiom of reciprocity the [n $(n-1) / 2]$ calculations in the black area are automatically done upon inputs into the cells above the diagonal.

The number of comparisons is determined by equation 2 :

$$
C=\frac{n(n-1)}{2}
$$

For this study's objectives with $\mathrm{n}=5$; number of pair wise comparisons is computed by equation 3 as: 


$$
C=\frac{5(5-1)}{2}=10
$$

For the 6 alternatives' comparison with respect to the control hierarchy, the number of pair wise combinations is computed by equation 4 as:

$$
C=\frac{6(6-1)}{2}=15
$$

These comparisons were made with respect to the given criterion of the control hierarchy and subsequently the importance weight of each factor was calculated.

\section{Synthesis of the Priorities}

The grids ensured the determination of the priority eigenvectors $(\omega)$ for each of the alternatives, for each control criterion as well as the relative priorities of the criteria themselves. Measures of central tendency were collected on the entries into the AHP grid. There are several methods for calculating the eigenvector. However, since there are many entries from various sources, the means were used to find the mathematical consensus. As it is typical in group situations, we used the geometric mean (Foster and Al-Dubaibi, 1995; Lai et. al, 1999; Lin and Hsu, 2007) to strike the average values to be used as final inputs into the AHP grid. Among its many attributes the geometric mean, like the median is able to manage extreme values better than the arithmetic mean. The geometric mean is computed by multiplying together the entries in each row of the matrix and then taking the $\mathrm{n}^{\text {th }}$ root of that product. Given a matrix of size $n$ with entries aij, the geometric means $(\mathrm{GM})$ were calculated by equation 5 as:

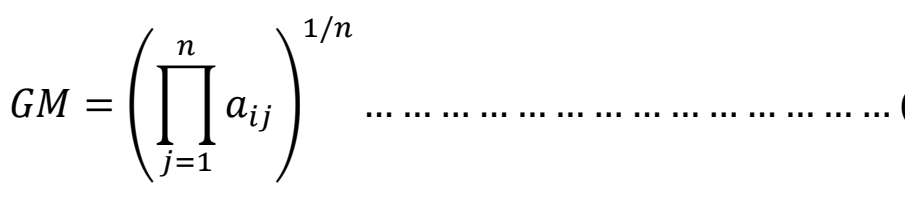

The geometric means were summed and that sum was used to normalize the eigenvector $\left(\omega_{i}\right)$ elements as indicated in equation 6 as: 


$$
\omega_{i}=\frac{\left(\prod_{j=1}^{n} a_{i j}\right)^{\frac{1}{n}}}{\sum_{i=1}^{n}\left(\prod_{j=1}^{n} a_{i j}\right)^{\frac{1}{n}}}
$$

\section{Testing for Consistency}

Usually to have obtained - omega $(\omega)$ as a resultant of the pairwise process should signify the end of the process. However, for matrices involving human judgment, the transitivity condition [aik = aijajk] does not always hold as human judgments are inconsistent to a greater degree. Thus there should be a way to determine the consistency of the omegas. The difference, if any, between $\lambda \max$, an approximate eigenvalue $\lambda$ of the eigenvector $\omega$ and the number of elements " $n$ " is an indication of the inconsistency of the judgments. If $\lambda \max =n$ then the judgments have turned out to be consistent. A Consistency Index (CI) was then computed from equation 7 as:

$$
C I=\frac{\lambda \max -\mathrm{n}}{n-1} .
$$

CI needs to be assessed against judgments made completely at random and Saaty (2008) has computed large samples of random indices (RI) as indicated in Table 6 (in Appendix) of increasing order. A true Consistency Ratio (CR) is calculated by dividing the Consistency Index for the set of judgments by the Index for the corresponding random matrix as indicated in equation 8

$$
C R=\frac{C I}{R I} .
$$

For the pair wise judgments to be credible, Saaty (2008) postulates that CR should be small with an upper bound of $10 \%$, with a CR of 0 meaning that the judgments are perfectly consistent.

After the grid has passed the tests of consistency as displayed by the Consistency Ratio (CR) of being less than $10 \%$, the normalized priority weights or eigenvectors $(\omega)$ were calculated by equation 9 as:

$$
A \omega=\lambda_{\max } \omega .
$$


Where each product of the eigenvector and the matrix $A$ is an estimate of $\lambda_{\max }$. An average of all these $\lambda_{\max } \mathrm{s}$ was then computed, using equation 10, as the representative $\lambda_{\max }$.

$$
\lambda_{\max }=\frac{1}{n} \sum_{i=1}^{n} \frac{(A \omega)_{i}}{\omega_{i}}
$$

\section{Study experiment description}

To determine the best internet service, consumers not only want the service with the lowest cost, but also want data at high speed so they can be part of internet activities such as video conferencing. They also do not want to wait for unduly long time installing the modem nor understanding manuals on how to troubleshoot simple issues. Again, consumers do not want a service that is unavailable when needed most. Besides, consumers are very much concerned with how quick they obtain technical support in using products from ISPs. These conflicting consumer requirements, largely, influence their choice of an ISP. Hence, this paper proposes a comprehensive framework in which a structured hierarchy is constructed with the appropriate attributes specified to provide an objective guidance for ISP evaluation. The analytical hierarchy process (AHP) method is applied to deal with ambiguities that may be involved in the assessment of ISP modem alternatives and relative importance weightings of attributes.

In ascertaining satisfaction criteria among consumers in their choice of an ISP, consumers who receive their internet service through modems were considered in the consumer satisfaction survey. Besides, a condition for being part of the survey was the ownership of a modem from any of the local ISPs. Ownership of a modem was considered a condition for respondents to demonstrate some degree of proficiency with the use of a modem. 150 respondents participated in the consumer satisfaction survey that allowed a comparison among the alternative ISPs (in respect of how well they meet consumer needs) as well as unravelling the critical consumer satisfaction criteria in the ISP market in Ghana. The respondents were students from universities in Ghana, with majority, preparing for an online Six-Sigma Course and hence were familiar with internet usage and service. Furthermore, the respondents were students who are already working in firms in Ghana, with some as senior executives, and were taking a first degree top up or pursuing a second bachelor's degree. Hence, this indicates a relatively fair representation of internet users in Ghana. 


\section{Obtaining Operational Statistics from Modems}

Respondents were supplied with additional modems, apart from their own original modems, through borrowing or swapping. The intention was to collect operational statistics from the diagnostic features of the different modems from alternative ISPs. A user of Modem1 was given another modem which was not Modem1 (own modem). User was then trained in how to use the second modem (Modem2) to collect operational statistics about the "cost perception, speed perception, customer support, user-friendliness and reliability" evaluation criteria, and then score these 2 modems using Saaty's Intensities of Importance Table. Table 2 shows, typical case of, the pairwise comparison exercise between two competing modems on the five criteria. In this case, there were 10 students (ST1-ST10) who pairwise-compared and scored the 2 ISPs [GLO and VODA (Vodafone)] data through their respective modems. The geometric means of VODA and GLO on the speed criterion were 3.296 and 1.231 respectively. These were then normalized and rounded to zero decimal place. These normalized values of 3 and 1 shown in Table 2 were then fed into the AHP grid.

[Table 2]

\section{Sample for Pairwise Comparison Exercise}

There were 15 different sub-samples in this study and a pairwise comparison of 6 modems. Hence, 150 Pairwise combinations were considered to populate the AHP grid across all five criteria. Table 5 (in Appendix) shows the required sample, the number that returned the questionnaire and the percentages involved.

Besides, Figure 3 indicates the AHP grid and the eigenvector $(\omega)$ with the priorities that resulted from the discussions in the group. 


\begin{tabular}{|c|c|c|c|c|c|c|}
\hline \multirow[b]{2}{*}{ MATRIX A } & \multicolumn{5}{|c|}{ Pairwise comparisons among CRITERIA } & \\
\hline & & & & & & \\
\hline CRITERIA & COST & SPEED & USABILITY & SUPPORT & RELIABILITY & \\
\hline COST & 1 & 4 & 8 & 9 & 7 & \\
\hline SPEED & $1 / 4$ & 1 & 3 & 7 & 3 & \\
\hline USABILITY & $1 / 8$ & $1 / 3$ & 1 & 3 & $1 / 2$ & \\
\hline SUPPORT & $1 / 9$ & $1 / 7$ & $1 / 3$ & 1 & $1 / 3$ & \\
\hline RELIABILITY & $1 / 7$ & $1 / 3$ & 2 & 3 & 1 & \\
\hline GEOMEAN & CRITERIA & $\boldsymbol{\omega}$ & Aw & $\lambda \max$ & $\mathrm{n}=$ & 5 \\
\hline 4.5803 & COST & 0.5761 & 3.03125 & 5.261307 & $\mathrm{Cl}$ & 0.0491 \\
\hline 1.7356 & SPEED & 0.2183 & 1.12056 & 5.132723 & & \\
\hline 0.5743 & USABILITY & 0.0722 & 0.37217 & 5.151466 & $\mathrm{RI}$ & 1.1200 \\
\hline 0.2814 & SUPPORT & 0.0354 & 0.18731 & 5.292443 & & \\
\hline 0.7784 & RELIABILITY & 0.0979 & 0.50365 & 5.144165 & CR & 0.0438 \\
\hline 7.9501 & $=$ SUM = & 1.0000 & $\begin{array}{l}\text { mean } \\
\lambda \_\max =\end{array}$ & 5.1964 & Result & Consistent \\
\hline
\end{tabular}

Figure 3: Pairwise comparisons among criteria

\section{Results and discussion}

As it is indicated in Table 5, there were 76 responses out of a total of 150. This constitutes an overall response rate of $51 \%$ as far as the survey is concerned with some variations across different modem pairs. There were very low responses especially for the less popular modems (Expresso, Airtel, GLO and Tigo) but the responses for the popular modems (MTN and Vodafone) were high as can be observed in Table 5. The less popular modems had low response rates mainly because they were relatively not easy to come by unlike the popular modems. The criteria used to evaluate the modems were pairwise-compared (see Figure 3) and referring to Saaty's (2008) intensities of importance, the following results were obtained:

i. Cost is deemed between moderate and strong importance than speed and thus receives a score of 4; cost is deemed between very strong and extreme importance than usability (8); cost is deemed definitely of more importance than support (9); cost is deemed much better and of demonstrated importance than reliability (7). 
i. $\quad$ Speed is deemed slightly better than usability or user-friendliness (3); much better than support (7) and slightly better than reliability (3).

ii. Usability is deemed slightly better than support (3) and between indifferent and slightly worse than reliability $(0.5)$

iii. Support is deemed slightly worse than reliability (0.33).

\section{Eigenvector ( $\omega$ ) of Criteria Calculation}

Multiplying together the entries in each row of the matrix and then taking the $\mathrm{n}^{\text {th }}$ root of that product gives a very good approximation of the eigenvector. The $\mathrm{n}^{\text {th }}$ roots were summed and that sum was used to normalize the eigenvector elements to add to 1.00 (Coyle, 2004). This approach thus delivered the geometric mean.

As indicated in Figure 3, the eigenvectors of the relative importance of cost, speed, usability, support and reliability are $0.576,0.218,0.072,0.035$, and 0.098 respectively. Thus, the rankings in terms of significance are Cost, Speed, Reliability, Usability and Support.

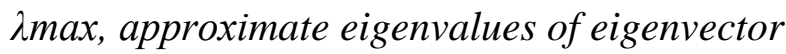

Subsequently the $\lambda \max$ was estimated so as to determine the Consistency Index and the Consistency Ratio.

We multiplied on the right, the matrix of judgments (A) by the eigenvector ( $\omega)$, thereby obtaining a new vector $\mathrm{A} \omega$ as in Figure 3. This was accomplished using the excel matrix MMULT function.

This vector of five elements $(3.03125,1.12056,0.37217,0.18731,0.50365)$ is the product $\mathrm{A} \omega$ and the AHP theory says that $A \omega=\lambda \max \omega$, so we got five estimates of $\lambda \max$ by dividing each component of $(0.576,0.218,0.072,0.035,0.098)$ by the corresponding eigenvector element. This gives $(5.261307,5.132723,5.151466,5.292443$, and 5.144165). The mean of these values is 5.196 and that is the estimate for $\lambda \max$. If any of the estimates for $\lambda \max$ turns out to be less than $\mathrm{n}$ or 5 in this case, then it indicates an error in the calculation, which is a useful check. However, in this study, all the values for $\lambda \max$ are above 5 . 


\section{Consistency Index}

The Consistency Index (CI) for the matrix was 0.0491. Finally the Consistency Ratio for the set of judgments was estimated using the CI for the corresponding value from large samples of matrices of purely random judgments using Table 6 , in which the upper row is the order of the random matrix, and the lower is the corresponding index of consistency for random judgments.

\section{Consistency Ratio}

Saaty (2008) argues that a CR $>0.1$ indicates that the judgments are at the limit of consistency though CRs > 0.1 (but not too much more) have to be accepted sometimes. A CR as high as, say, 0.9 would mean that the pairwise judgments are just about random and are completely untrustworthy. The alternatives, which in this case are the modems, were then evaluated on the five criteria - Cost, Speed, Usability, Support and Reliability.

\section{Calculation of Criteria Priorities}

The number of pair wise combinations for the 6 alternative ISPs with respect to the cost criterion, is 15 (See equation 4). The resultants of the computations are shown in Figure 4. The eigenvector $\omega$ shows that GLO is the best with an eigenvalue of 0.347 , closely followed by Espresso (0.324). The next in line are TIGO (0.137), Airtel (0.076), Vodafone (0.066) and MTN (0.05). The Consistency Index is 0.0648, the Random Index value here is 1.24. The computed value of the Consistency Ratio is $0.0522<0.1$ and thus consistent. The evaluation of the alternatives on the other criteria mirrors the calculations of the cost criterion because they are all of dimension $n=6$. The results of the calculations of the five criteria and six alternatives are indicated in Table 3. The figures in parentheses, in Table 3, indicate the ranks of the alternatives 


\begin{tabular}{|c|c|c|c|c|c|c|}
\hline COST & AIRTEL & ESPRESSO & GLO & MTN & TIGO & VODAFONE \\
\hline AIRTEL & 1 & $1 / 4$ & $1 / 5$ & 2 & $1 / 2$ & 1 \\
\hline ESPRESSO & 4 & 1 & 1 & 3 & 5 & 5 \\
\hline GLO & 5 & 1 & 1 & 5 & 3 & 6 \\
\hline MTN & $1 / 2$ & $1 / 3$ & $1 / 5$ & 1 & $1 / 4$ & $1 / 2$ \\
\hline TIGO & 2 & $1 / 5$ & $1 / 3$ & 4 & 1 & 3 \\
\hline VODAFONE & 1 & $1 / 5$ & $1 / 6$ & 2 & $1 / 3$ & 1 \\
\hline GEOMEAN & ALTERNATIVES & $\omega$ & $A \omega$ & $\lambda \max$ & $\mathrm{n}=$ & 6 \\
\hline 0.607 & AIRTEL & 0.0761 & 0.46151 & 6.064 & $\mathrm{Cl}$ & 0.0648 \\
\hline 2.5873 & ESPRESSO & 0.3244 & 2.13725 & 6.588 & & \\
\hline 2.7682 & GLO & 0.3471 & 2.10923 & 6.077 & $\mathbf{R I}$ & 1.24 \\
\hline 0.4011 & MTN & 0.0503 & 0.33305 & 6.622 & & \\
\hline 1.0815 & TIGO & 0.1356 & 0.86903 & 6.409 & & \\
\hline 0.5302 & VODAFONE & 0.0665 & 0.41112 & 6.184 & CR & 0.0522 \\
\hline 7.9754 & $=$ SUM = & 1.0000 & $\operatorname{mean} \lambda \max =$ & 6.3238 & Result & Consistent \\
\hline
\end{tabular}

Figure 4: Pairwise comparisons among alternatives on cost criterion

[Table 3]

\section{Overall Rankings}

After computing the normalized priority weights or eigenvectors for each pair-wise comparison matrix of the AHP hierarchy as in Figure 4, the next step was to synthesize the local priority weights of criteria and sub criteria for obtaining the set of global composite priorities (Lin and Hsu, 2007). Thus to determine the global rankings of best service by an ISP through a modem with the criteria and objectives identified, the Supermatrix was developed as indicated in Figure 5. The columns in the super matrix are the eigenvectors of the five criteria. Using the same MMULT function in Excel, the matrix " $\mathrm{A}$ " was vector multiplied by the column vector of the priorities of the criteria to obtain the matrix AX.

The resultant matrix AX clearly shows the order of preference of the modems. GLO is ranked number first (1). It appears GLO ranked first (1) due to its strong advantage on cost. The cost 
criterion received the highest weighted score of 58\%. Thus any modem that performed well on this criterion appears to do well in the overall rankings. GLO and Espresso seem to have the best performance on cost and that explains their strong representations in the overall rankings. Cost as a criterion or attribute of internet service provision appears to have the highest weighted score, mainly, because the level of income of most consumers, in Ghana, is low relative to the income level of developed countries. Hence, in such an environment, consumers (in their decision making) are likely to emphasize the cost attribute of products they consume, particularly internet service which is not considered as a basic need or necessity. This result seems to differ from what pertains in developed countries or economies (see studies of Tan and Teo, 1998; Erevelles et al., 2003 and $\mathrm{Li}$ et al., 2008) where the cost criteria or attribute of internet service is considered "basic" by consumers in their choice of an ISP. This is perhaps explained by two reasons. Firstly, the relatively high income level of consumers in such economies and secondly the relatively high operational efficiencies by the ISPs which eventually translate into lower operational cost that gets transferred to consumers in the form of lower prices. In most developing economies, such as Ghana and other Sub-Saharan African countries, where lack of infrastructure is still a daunting challenge among other challenges, the operational efficiencies of ISPs can be reduced resulting in relatively high operational cost. Apart from cost, internet speed (weighted score of 22\%) seems to be another criterion that consumers place emphasis on. Consumers seem to attach moderate importance to internet reliability (weighted score of $10 \%$ ). This moderate importance attached to internet reliability by consumers in Ghana differs from the expectations of consumers in developed economies, particularly UK where McCue (2006) indicates that more than half of internet consumers would switch to a different ISP to have better reliability. On the other hand, internet service support (weighted score of 4\%) and usability or user-friendliness (weighted score of 7\%) as features of internet service provision do not appear to be largely emphasized by consumers. The low emphasis on internet service support and usability or user-friendliness by customers in Ghana appear to be in contrast with results in Thailand, as reported by Thaichon et al. (2014), where internet service quality (partly in the form of customer service support and technical support, website information support) engenders overall service satisfaction, trust and commitment to ISP by customers. Internet service support and usability or user-friendliness being less emphasized, as found out by this study in Ghana, does not seem to be 
surprising as it, only, reflects a business environment where customer centeredness appears to be neglected by a large proportion of vendors and hence not too much of it expected by consumers.

\begin{tabular}{|c|c|c|c|c|c|}
\hline \multicolumn{6}{|l|}{ A } \\
\hline MODEM & COST & SPEED & USABILITY & SUPPORT & RELIABILITY \\
\hline AIRTEL & $8 \%$ & $24 \%$ & $23 \%$ & $34 \%$ & $15 \%$ \\
\hline ESPRESSO & $32 \%$ & $10 \%$ & $5 \%$ & $13 \%$ & $9 \%$ \\
\hline GLO & $35 \%$ & $22 \%$ & $18 \%$ & $18 \%$ & $23 \%$ \\
\hline MTN & $5 \%$ & $18 \%$ & $18 \%$ & $20 \%$ & $18 \%$ \\
\hline TIGO & $14 \%$ & $4 \%$ & $27 \%$ & $9 \%$ & $8 \%$ \\
\hline VODAFONE & $7 \%$ & $22 \%$ & $11 \%$ & $5 \%$ & $26 \%$ \\
\hline \multicolumn{2}{|l|}{$x$} & & \multicolumn{3}{|l|}{$A X$} \\
\hline PRIORITIES & CRITERIA & & MODEM & VALUE & RANK \\
\hline $58 \%$ & COST & & AIRTEL & $14 \%$ & 3 \\
\hline $22 \%$ & SPEED & & ESPRESSO & $23 \%$ & 2 \\
\hline $7 \%$ & USABILITY & & GLO & $29 \%$ & 1 \\
\hline $4 \%$ & SUPPORT & & MTN & $11 \%$ & 6 \\
\hline $10 \%$ & RELIABILITY & & TIGO & $12 \%$ & 5 \\
\hline & & & VODAFONE & $12 \%$ & 4 \\
\hline
\end{tabular}

Figure 5: Supermatrix of Eigenvectors (w)

\section{Conclusion}

The study illustrates the development of an AHP-based model for evaluating the ISPs of Ghana, a Sub-Saharan African country, on their service offerings through the USB modem with the view to finding out which vendor offers the best service in the Ghanaian environment. Besides, the approach (as theoretical contribution to literature) sought to unravel the critical underlying consumer satisfaction in ISP markets in developing economies, particularly Ghana, so as to inform the marketing strategies and also ensure focused service deliveries by the ISPs. Hence, five attributes or features of ISP modems, based on literature agreement, were used as the main evaluating criteria. The study reveals that GLO (ranked first) and Expresso (ranked second) are the best in respect of the evaluating criteria. Their performances can, largely, be explained by their advantage on cost as consumers prioritized cost, most, among all the other criteria. Incidentally, these best performing ISPs seem to have the lowest market shares (GLO - 2.7\% 
and Expresso - 0.3\%) in Ghana due to their relatively low coverage area. MTN, the worst performing ISP in respect of the evaluating criteria has the highest market share $(50.5 \%)$ as a result of having the highest coverage area in Ghana. Hence, GLO and Expresso would need to work on increasing their respective coverage areas in order to improve on their market shares.

Besides, since it appears that the critical consumer requirements with respect to internet service consumption in Ghana are cost and speed. Hence, existing ISPs would have to focus on reducing business operation costs and subsequently transfer the benefits to consumers in the form of lower prices to stay competitive. This could be achieved by ensuring effective and efficient supply chains. Again, ISPs must invest in infrastructure that will deliver speed in internet provision. On the part of the government, there will be the need to develop and maintain an enabling and business-friendly environment by ensuring sound macro-economic conditions and developing essential economic infrastructure. Such an environment will boost the operational efficiencies of the ISPs which will translate into lower operational costs and hence lower prices of internet service provision. It is expected that, if the right business environment is provided and internet cost is lowered coupled with a rise in the income levels of consumers, the underlying consumer satisfaction criteria would shift from - mainly - cost to other criteria such as speed, reliability, customer support and usability as the case is in developed economies.

\section{Limitations and recommendations for future research}

A minor drawback of this study is the use of Excel instead of a dedicated AHP tool such as Logical decisions or Expert Choice. This limited any attempt at serious sensitivity analyses. Not too many people own more than one modem thus financial costs were incurred in equipping the participants with additional modems. There had to be a lot of modem swapping to cut down on cost. Swapping modems for respondents created proficiency challenges of the diagnostics of the swapped modem for respondents. This could potentially affect the validity of the responses from respondents.

Availability or coverage is a criterion to be considered in future studies because some of the ISPs have short reaches and cannot be accessed by people outside the major cities. Hence, even though an ISP may perform well on the five evaluating criteria considered in this study, the criterion of availability or coverage could affect the overall competitiveness of the ISP. Such an 
effect needs to be further analyzed. Besides, some of the criteria may be related; for example, usually the faster the service the higher the cost. Therefore, a methodology like Analytic Network Process (ANP) which incorporates feedback is recommended to be used in future studies to address the issue of relatedness of the criteria. Also, using fuzzy theory for assessment of the criteria can reduce ambiguities and uncertainties that are inherent in the qualitative evaluation.

\section{References}

Adomi, E. E (2005). "Internet Development and Connectivity in Nigeria", Program, Vol. 39, No.3, pp. 257-268.

Byun, D. H. (2001), "The AHP approach of selecting an automobile purchase model", Information and Management, Vol. 38, No. 5, pp. 289-297.

Chow, C. C. and Luk, P. (2005), "A strategic service quality approach using analytic hierarchy process”, Managing Service Quality: An International Journal, Vol. 15, No. 3, pp. 278-289.

Coyle, G. (2004), Practical Strategy, Prentice Hall, Harlow, UK.

Dyer, R. F. and Forman, E. H. (1992), "Group decision support with the analytic hierarchy process”, Decision Support Systems Vol.8, No. 2, pp. 99-124.

Eldrandaly K. (2007), "GIS software selection: A multi-criteria decision making approach," Applied GIS, Vol. 3, No. 5, pp. 1-19.

Erevelles, S., Srinivasan, S. and Rangel, S. (2003), "Consumer Satisfaction for Internet Service Providers: An Analysis of Underlying Processes", Information Technology and Management, Vol.4, No.1, pp. 69-89.

Ferretti, V. (2011), “A Multi-criteria spatial decision support system for landfill siting”, Journal Of Multi-Criteria Decision Analysis. Vol.18, No.5-6, pp. 231-252.

Forgionne, G. A., Kohli, R. and Jennings, D. (2002), “An AHP analysis of quality in AI and DSS journals", Omega, Vol. 30, No. 3, pp.171-183.

Forman, E. H. and Gass, S. L., (2001), "The analytic hierarchy process- An exposition", Operations Research., Vol. 49, No. 4, pp. 469-486.

Foster B. and Al-Dubaibi, A. (1995), "An axiomatic approach to pairwise comparisons". Working paper. Department of Mathematics and Statistics, Brunel University, London. 
Frimpon, M. (2016), "Structured Rankings of Internet Service Providers on Data and Price in Ghana”, International Journal of Business and Management, Vol. 11, No. 5, pp 271-282.

Geneletti, D. (2010), "Combining stakeholder analysis and spatial multi-criteria evaluation to select and rank inert landfill sites", Waste Management, Vol. 30, No. 2, pp. 328-337.

Goh, A. (1996), "Service providers invest millions to stay ahead", The Straits Times, 11 November, p. 35.

Guerrero, M. (2015). “The Impact of Internet Connectivity on Economic Development in SubSaharan Africa", Available at http://partnerplatform.org/eps-peaks (accessed 10 November 2016)

Guh, Y. (2009), "An Additive Scale Model for the Analytic Hierarchy Process", International Journal of Information and Management Science, Vol 20, No1, pp. 71-88.

Guh Y. Y, Po, R. and Lou, K. (2009), “An Additive Scale Model for the Analytic Hierarchy Process", International Journal of Information and Management Sciences, Vol. 20, No.1, pp. 7188.

Hussain, H., Kehl, D., Lennett, B., Li, C. and Lucey, P. (2012), "The Cost of Connectivity: A Comparison of High-speed Internet Prices in 22 cities worldwide”, Open Technology Institute, Washington D.C., Available at http://www.newamerica.net (accessed 15 December 2016)

Kim, C. S. and Yoon, Y. (1992), "Selection of a good expert system shell for instructional purposes in business", Information and Management, Vol. 23, No.5, pp. 249-262.

Lai, V. S., Trueblood R. P. and Wong, B. K. (1999), "Software selection: a case study of the application of the AHP to the selection of a multimedia authoring system", Information \& Management Vol. 36, No. 4, pp. 221-232.

Li, S. T., Shue, L. Y. and Lee, S. F. (2008), "Business Intelligence Approach to Supporting Strategy-making of ISP Service Management”, Expert Systems with Applications, Vol. 35, No.1, pp. 739-754.

Lin, H. and Hsu, P. (2007), "Application of the Analytic Hierarchy Process on data warehouse system selection decisions for small and large enterprises in Taiwan" International Journal of The Computer, the Internet and Management, Vol. 15.No.3, pp. 73-93.

Mamaghani, F. (2002), "Evaluation and selection of an antivirus and content filtering software", Information Management and Computer Security, Vol.10, No.1, pp. 28-32.

McCue (2006), "TalkTalk is UK's least-liked broadband provider", Available at: http://www.zdnet.com/article/talktalk-is-uks-least-liked-broadband-provider/ (last accessed, February 10, 2017). 
Minges, M., Briceño-Garmendia, C., Williams, M., Ampah, M., Camos, D. and Shkratan, M. (2009), "Information and Communications Technology in Sub-Saharan Africa: A Sector Review”, available at: http://www.eu-africa-infrastructure-tf.net/attachments/library/aicdbackground-paper-10-ict-sect-summary-en.pdf (accessed 10 June 2016).

Mirkin, B.G. (1979), Group Choice, Halsted Press, New York.

Muralidar, K. and Santhanam, R. (1990), "Using the analytic hierarchy process for information system project selection”, Information and Management, Vol. 18, No.1, pp. 87-95.

National Communication Authority (NCA) (2014), "Market share statistics", available at: http://www.nca.org.gh/40/105/Market-Share-Statistics.html (accessed 20 July 2014).

Ngai, E. W. T. and Chan E. W. C. (2005), "Evaluation of knowledge management tools using AHP”, Expert Systems with Applications, Vol. 29, No. 4, pp. 889-899.

Ossadnik, W. and Lange, O. (1999), "AHP-based evaluation of AHP software", European Journal of Operational Research, Vol.118, No.3, pp.578-588.

Rehman, Z. u., Hussain, F. K. and Hussain, O. K. (2011) "Towards Multi-criteria Cloud Service Selection," Innovative Mobile and Internet Services in Ubiquitous Computing (IMIS), 2011 Fifth International Conference on Innovative Mobile and Internet Services in Ubiquitous Computing, IMIS 2011, Seoul, Korea, June 30-July 02, 2011, Seoul, pp. 44-48.

Reiffel, R. (2011), "USB Modems in Ghana", available at: http://www.docstoc.com/docs/124694490/USB-Modems-In-Ghana (accessed 10 June 2015).

Saaty, T. L. (1994), "Highlights and critical points in the theory and application of the analytic hierarchy process", European Journal of Operational Research, Vol. 74, No. 3, pp.426-447.

Saaty, T. L. (2008), "Relative measurement and its generalization in decision making: Why pairwise comparisons are central in mathematics for the measurement of intangible factors - The Analytic Hierarchy/Network Process", Review of the Royal Spanish Academy of Sciences, Series A, Mathematics, Vol 102, No. 2, pp. 251-318.

Sanou B. (2013), "ICT fact and figures: the world in 2013", available at: www.itu.int/ict (accessed 5 March 2015).

Schniedejans, M. J. and Wilson, R. L. (1991), "Using the analytic hierarchy process and goal programming for information system project selection", Information and Management, Vol. 20, No. 5, pp. 333-342. 
Schumann R. and Kende, M. (2013), "Lifting barriers to internet development in Africa: Suggestions for improving Connectivity", available at: www.analysysmason.com (accessed 15 May 2015).

Shin, D.H. (2009), "A cross-national study of mobile internet services: a comparison of US and Korean mobile internet users", Journal of Global Information Management, Vol. 17 No. 4, pp. 29-54.

Singhal, M. and Shukla, A. (2012), "Implementation of location based services in android using GPS and web services" International Journal of Computer Science Issues, Vol. 9, No. 1, pp. 237-242.

Smith, A. G. (1997), "Testing the Surf: Criteria for Evaluating Internet Information Resources." The Public-Access Computer Systems Review, Vol. 8, No. 3, pp 5-23.

Tam, M. C. Y., and Tummala, V. M. R. (2001), "An application of the AHP in vendor selection of a telecommunications system", Omega, Vol. 29, No.2, pp.171-182.

Tan, M. and Teo, T. S. H. (1998), "Factors Influencing the Adoption of the Internet", International Journal of Electronic Commerce, Vol. 2, No. 3, pp. 5-18.

Thaichon, P., Lobo, A. and Mitsis, A. (2014). “An empirical model of home internet services quality in Thailand", Asia Pacific Journal of Marketing and Logistics, Vol. 26 No. 2, pp. 190210

Vlachos, A. and Vrechopoulos, P. (2008), "Determinants of behavioral intentions in the mobile internet services market”, Journal of Services Marketing, Vol. 22 No. 4, pp. 280-291.

Zeng, L., Benatallah, B., Dumas, M., Kalagnanam, J. and Sheng, Q. Z. (2003), "Quality driven web services composition. In Proceedings of the 12th international conference on World Wide Web, ACM, New York, pp. 411-421. 
Table 1: ISP selection criteria and sources

\begin{tabular}{|c|c|}
\hline ISP selection criteria & Source \\
\hline Cost & $\begin{array}{l}\text { Frimpon (2016); Rehman, et al. (2011); Li et } \\
\text { al. (2008); Adomi (2005); Zeng et al. (2003); } \\
\text { Erevelles et al. (2003); Tan and Teo (1998); } \\
\text { Smith (1997); Goh (1996) }\end{array}$ \\
\hline Speed & $\begin{array}{l}\text { Li et al. (2008); Erevelles et al. (2003); Goh } \\
\text { (1996): Tan and Teo (1998); Vlachos and } \\
\text { Vrechopoulos (2008); Thaichon et al. (2014) }\end{array}$ \\
\hline Usability & $\begin{array}{l}\text { Li et al. (2008); Erevelles et al. (2003); Tan } \\
\text { and Teo (1998); Smith (1997) }\end{array}$ \\
\hline Reliability & $\begin{array}{l}\text { Li et al. (2008); McCue (2006); Erevelles et al. } \\
\text { (2003); Zeng et al. (2003); Tan and Teo } \\
\text { (1998); Goh (1996); Vlachos and } \\
\text { Vrechopoulos (2008); Thaichon et al. (2014) }\end{array}$ \\
\hline Support & $\begin{array}{l}\text { Li et al. (2008); Erevelles et al. (2003); Tan } \\
\text { and Teo (1998); Goh (1996); Vlachos and } \\
\text { Vrechopoulos (2008); Thaichon et al. (2014) }\end{array}$ \\
\hline
\end{tabular}


Table 2: Pairwise comparison of 2 ISPs on the five criteria

\begin{tabular}{|c|c|c|c|c|c|c|c|c|c|c|}
\hline CRITERIA $\rightarrow$ & \multicolumn{2}{|c|}{ COST } & \multicolumn{2}{c|}{ SPEED } & \multicolumn{2}{c|}{ USABILITY } & \multicolumn{2}{c|}{ SUPPORT } & \multicolumn{2}{c|}{ RELIABILITY } \\
\hline RESPONDENTS & VODA & GLO & VODA & GLO & VODA & GLO & VODA & GLO & VODA & GLO \\
\hline ST1 & 1 & 7 & 7 & 1 & 1 & 7 & 1 & 5 & 4 & 1 \\
\hline ST2 & 1 & 7 & 4 & 1 & 1 & 5 & 1 & 5 & 3 & 1 \\
\hline ST3 & 1 & 4 & 1 & 4 & 1 & 7 & 1 & 7 & 1 & 2 \\
\hline ST4 & 1 & 9 & 9 & 1 & 1 & 6 & 2 & 1 & 1 & 1 \\
\hline ST5 & 1 & 4 & 1 & 2 & 1 & 5 & 1 & 5 & 2 & 1 \\
\hline ST6 & 1 & 6 & 2 & 1 & 1 & 5 & 1 & 7 & 2 & 1 \\
\hline ST7 & 1 & 5 & 5 & 1 & 2 & 1 & 1 & 5 & 1 & 2 \\
\hline ST8 & 1 & 5 & 3 & 1 & 1 & 5 & 1 & 7 & 2 & 1 \\
\hline ST9 & 1 & 5 & 4 & 1 & 2 & 1 & 2 & 1 & 3 & 1 \\
\hline ST10 & 1 & 7 & 5 & 1 & 1 & 8 & 1 & 7 & 1 & 3 \\
\hline GEOMEAN & 1.000 & 5.713 & 3.296 & 1.231 & 1.149 & 4.137 & 1.149 & 4.146 & 1.762 & 1.282 \\
\hline $\begin{array}{c}\text { NORMALIZED } \\
\text { GEOMEAN }\end{array}$ & 1 & 6 & 3 & 1 & 1 & 4 & 1 & 4 & 1 & 1 \\
\hline
\end{tabular}

Table 3: Eigenvectors, eigenvalues, rankings and consistency ratios of the five criteria

\begin{tabular}{|l|l|l|l|l|l|}
\hline $\begin{array}{l}\text { SERVICE } \\
\text { PROVIDER }\end{array}$ & COST & SPEED & USABILITY & SUPPORT & RELIABILITY \\
\hline AIRTEL & $0.076(4)$ & $0.244(1)$ & $0.227(2)$ & $0.344(1)$ & $0.153(4)$ \\
\hline VODAFONE & $0.066(5)$ & $0.220(2)$ & $0.108(5)$ & $0.052(6)$ & $0.259(1)$ \\
\hline GLO & $0.347(1)$ & $0.217(3)$ & $0.175(3)$ & $0.181(3)$ & $0.231(2)$ \\
\hline MTN & $0.050(6)$ & $0.181(4)$ & $0.175(3)$ & $0.200(2)$ & $0.183(3)$ \\
\hline ESPRESSO & $0.324(2)$ & $0.098(5)$ & $0.048(6)$ & $0.130(4)$ & $0.090(5)$ \\
\hline TIGO & $0.137(3)$ & $0.041(6)$ & $0.265(1)$ & $0.093(5)$ & $0.084(6)$ \\
\hline CR & 0.052 & 0.087 & 0.078 & 0.082 & 0.075 \\
\hline
\end{tabular}




\section{Appendix}

Table 4: Combination of different versions of Saaty's intensities of importance

\begin{tabular}{|c|c|c|c|}
\hline $\begin{array}{c}\text { Intensity of } \\
\text { importance }\end{array}$ & Judgment & Judgment 1 & Judgment 2 \\
\hline 1 & Equal importance & $\begin{array}{c}\text { Two activities } \\
\text { contribute equally to } \\
\text { the objective }\end{array}$ & Indifferent \\
\hline 3 & $\begin{array}{c}\text { Moderate } \\
\text { importance of } \\
\text { one over another }\end{array}$ & $\begin{array}{c}\text { The judgment is to } \\
\text { favor one activity over } \\
\text { another, but it is not } \\
\text { conclusive }\end{array}$ & Slightly better \\
\hline 5 & $\begin{array}{c}\text { Strong or } \\
\text { essential } \\
\text { importance }\end{array}$ & $\begin{array}{c}\text { The judgment is to } \\
\text { strongly favor one } \\
\text { activity over another }\end{array}$ & Better \\
\hline 7 & $\begin{array}{c}\text { Very strong or } \\
\text { imponstrated } \\
\text { importance }\end{array}$ & $\begin{array}{c}\text { Conclusive judgment } \\
\text { as to the importance } \\
\text { of one activity over } \\
\text { another }\end{array}$ & Much Better \\
\hline $2,4,6,8$ & $\begin{array}{c}\text { Intermediate } \\
\text { values }\end{array}$ & $\begin{array}{c}\text { When compromise is } \\
\text { needed }\end{array}$ & $\begin{array}{c}\text { Intermediate values } \\
\text { used to interpolate } \\
\text { between adjacent } \\
\text { scale values }\end{array}$ \\
\hline & $\begin{array}{c}\text { The judgment in favor } \\
\text { of one activity over } \\
\text { another is of the } \\
\text { highest possible order } \\
\text { of affirmation }\end{array}$ & Definitely Much \\
Better
\end{tabular}


Table 5: Pairwise combinations required to populate AHP grid

\begin{tabular}{|c|c|c|c|c|}
\hline \# & $\begin{array}{l}\text { PAIRWISE COMBOS of } 2 \\
\text { ISPS }\end{array}$ & SAMPLED & RETURNED & \%RETURNED \\
\hline 1 & [GLO, VODAFONE] & 10 & 10 & $100 \%$ \\
\hline 2 & {$[\mathrm{GLO}, \mathrm{MTN}]$} & 10 & 6 & $60 \%$ \\
\hline 3 & [GLO, AIRTEL] & 10 & 7 & $70 \%$ \\
\hline 4 & [GLO, TIGO] & 10 & 5 & $50 \%$ \\
\hline 5 & [GLO, ESPRESSO] & 10 & 4 & $40 \%$ \\
\hline 6 & [VODAFONE, MTN] & 10 & 10 & $100 \%$ \\
\hline 7 & [VODAFONE, AIRTEL] & 10 & 4 & $40 \%$ \\
\hline 8 & [VODAFONE, TIGO] & 10 & 5 & $50 \%$ \\
\hline 9 & [VODAFONE, ESPRESSO] & 10 & 3 & $30 \%$ \\
\hline 10 & [MTN, AIRTEL] & 10 & 6 & $60 \%$ \\
\hline 11 & [MTN, TIGO] & 10 & 4 & $40 \%$ \\
\hline 12 & [MTN, ESPRESSO] & 10 & 5 & $50 \%$ \\
\hline 13 & [AIRTEL, TIGO] & 10 & 3 & $30 \%$ \\
\hline 14 & [AIRTEL, ESPRESSO] & 10 & 2 & $20 \%$ \\
\hline \multirow[t]{2}{*}{15} & [TIGO, ESPRESSO] & 10 & 2 & $20 \%$ \\
\hline & TOTALS & 150 & 76 & $51 \%$ \\
\hline
\end{tabular}

Table 6: Random Indices (RI)

\begin{tabular}{|l|l|l|l|l|l|l|l|l|l|}
\hline $\mathrm{n}=$ & 2 & 3 & 4 & 5 & 6 & 7 & 8 & 9 & 10 \\
\hline $\mathrm{RI}=$ & 0 & 0.58 & 0.9 & 1.12 & 1.24 & 1.32 & 1.41 & 1.45 & 1.51 \\
\hline
\end{tabular}

